\title{
LA GUERRA COMO TEMA TRASCENDENTAL DE LA HISTORIA DE LA FILOSOFÍA
}

\author{
WAR AS MOMENTOUS ISSUE OF HISTORY OF PHILOSOPHY
}

\author{
Andrés González Gómez \\ IES Doctor Balmis, Alicante (España)
}

Recibido: 20-05-2012

Aceptado: 26-06-2012

Resumen: Se exponen dos concepciones opuestas de la Historia de la Filosofía que guardan correspondencia cada una de ellas, con la Antropología Filosófica y con la Filosofía de la Historia respectivamente. Y se defiende una tesis, según la cual, la concepción de la Historia de la Filosofía que es indisociable de la Filosofía de la Historia, encuentra en el contenido de la Idea de Guerra el fundamento causal de la concatenación polémica entre los sistemas filosóficos históricamente dados.

Palabras-clave: Historia de la Filosofía, Antropología Filosófica, Filosofía de la Historia, guerra, racionalidad institucional, semántica, pragmática, totalidades distributivas, totalidades atributivas, géneros porfirianos, géneros plotinianos, nomotético, idiográfico, unidad, multiplicidad, lineal, cíclico, materialismo, idealismo.

\begin{abstract}
Two opposing conceptions of the history of philosophy that keep each correspondence with the Philosophical Anthropology and the Philosophy of History are discussed respectively. And a thesis, according to which the conception of the history of philosophy that is inseparable from the Philosophy of History, in the content of the Idea of War defends the causal basis of the controversy between the philosophical systems concatenation historically given. Key-words: History of Philosophy, Philosophical Anthropology, Philosophy of History, war, institutional rationality, semantics, pragmatics, distributive wholes wholes attributive, Porfirian genres plotinianos genres, nomothetic, idiographic, unity, multiplicity, linear, cyclic, materialism , idealism.
\end{abstract}


$1 \S$. Para exponer de forma ordenada las razones que, desde mi punto de vista, explican por qué la «historia de la filosofía» (en adelante «HF») está internamente vinculada a la guerra, hasta el punto de poder considerar a ésta como el hilo conductor con el que se puede entretejer todo el polémico entramado institucional articulado por dicha "historia institucional» (razones que, dicho sea de paso, seguramente sentarán mejor a los historiadores que a los filósofos), he de comenzar mi exposición partiendo de una distinción fundamental que separa disyuntivamente dos concepciones opuestas de la «historia de la filosofía».

$\mathrm{Al}$ partir de esta distinción fundamental entre dos concepciones opuestas de la "historia de la filosofía», pretendo evitar generar confusión desde el principio, pues la tesis expresada en el enunciado titular de mi comunicación (La guerra como tema trascendental de la historia de la filosofía), se refiere inmediatamente, de un modo exclusivo, a una de estas dos concepciones de la «historia de la filosofía» y no a la otra.

Estas dos concepciones de la historia de la filosofía mantienen entre sí una relación de oposición que calificaré como dioscúrica. ¿Qué quiere decir esto? Quiere decir que cuando arrojamos luz sobre la naturaleza del campo de la historia de la filosofía iluminándolo con la potencia clarificadora del enfoque característico de una de estas dos concepciones, inmediatamente la luz arrojada sobre dicho campo por el enfoque de la concepción contraria se apaga completamente.

La razón de ser de esta relación dioscúrica entre las dos concepciones opuestas de la HF, se encuentra en la serie de criterios dicotómicos usados para construir la distinción crítica entre ellas.

Esta serie de criterios dicotómicos es la siguiente:

1. Totalidades distributivas / Totalidades atributivas.

2. Géneros porfirianos / Géneros plotinianos.

3. Nomotético / Idiográfico.

4. Lo Múltiple / lo Uno.

5. Lo Cíclico / lo Lineal.

6. Lo Discontinuo / lo Continuo.

7. Lo Isológico / lo Sinalógica. 


\begin{tabular}{|l|l|}
\hline \multicolumn{2}{|c|}{ CONCEPCIONES DIOSCÚRICAS HISTORIA DE LA FILOSOFÍA } \\
\hline \multicolumn{1}{|c|}{ CONCEPCIÓN «A» } & CONCEPCIÓN «B» \\
\hline $\begin{array}{l}\text { Totalidades distributivas } \\
\text { Géneros porfirianos. } \\
\text { Nomotético. } \\
\text { Múltilpe. } \\
\text { Cíclico. } \\
\text { Discontinuo. } \\
\text { Isología. }\end{array}$ & Totalidades atributivas. \\
& Géneros plotinianos. \\
& Úniográfico. \\
& Lineal. \\
& Continuo. \\
& Sinalogía. \\
\hline
\end{tabular}

$2 \S$. Según la «concepción A», la HF sería una totalización distributiva de múltiples géneros porfirianos de filosofía, constituidos cada uno de ellos en ciclos independientes históricamente discontinuos, sin conexión causal entre ellos, pero en los que se repiten análogamente, por homología, ciertas regularidades nomotéticas de carácter cultural cuya difusión globalizadora de los ciclos distributivos permitiría atribuir a la identidad del todo, por isología, una cierta unidad cultural caracterizada por la homogenidad entre sus partes.

Según las notas características de esta "concepción A», la HF sería antes una «Historia gnoseológica que se escribe» con pretensión de veracidad, que una «historia ontológica realmente acontecida». Desde esta "Historia escrita de la HF», se pretende reflejar verazmente aquello que, desde su convencional enclasamiento, cada filosofía histórica ha aportado positivamente a la construcción de la verdad global que ha ido desplegando el saber de la disciplina con el paso del tiempo.

Ahora bien, este reflejo de la verdad desplegada por la Historia escrita de la disciplina, nos muestra globalmente al campo de la HF en un estado lisológico; es decir: nos lo muestra en un estado que oscurece la presencia en dicho campo del contenido morfológico de polémicas que, de tenerlas presente, nos mostrarían a las filosofías históricas realmente existentes como cuerpos de doctrina institucionalizados que luchan a muerte entre sí porque cada uno 
de ellos, idiográficamente considerado, es una singularidad sistemática de filosofía institucional que se desarrolla históricamente desplegando el proyecto fundamental de querer imponerse sobre las demás singularidades de su misma constelación semántica con el objetivo llegar a ser, algún día, la única forma de filosofía que logra sobrevivir institucionalmente dentro del contexto político que las envuelve a todas, el Estado (en su forma Imperial principalmente).

Por tanto, podría afirmarse que dicha reflexión veraz de la pretendida verdad global del saber contenido en toda la HF distributivamente considerada, es una apariencia configuradora de la presencia de un vacio de polémica que no es real.

Desde esta «concepción A», antes gnoseológica que ontológica de la HF, concepción que nos presenta el campo del saber filosófico históricamente desplegado en un estado lisológico respecto de su estado morfológico correlativo, la HF se nos ofrece como un saber doxográfico petrificado en el pretérito perfecto en diversos estratos periodológicos que pueden ser percibidos apotéticamente (a distancia) por el historiador desde la plataforma móvil de su presente práctico. Estos estratos periodológicos son los ciclos análogos distributivos, conceptualizados historiográficamente como edades o etapas inconexas de la $\mathrm{HF}$ (edad antigua, edad media y edad moderna). En virtud de esta desconexión causal entre las edades o etapas de esta Historia de la Filosofía, sería necesario sistematizar por separado los diferentes géneros porfirianos de filosofía. Así, según esto, el todo distributivo de la HF se dividiría taxonómicamente, de un modo inmediato, en una "HF Antigua» por un lado, una «HF medieval» por otro $\mathrm{y}$, finalmente, por otro lado, en una «HF moderna».

En definitiva: esta «concepción A» nos presenta una HF dotada de un contenido semántico que se presta a ser envuelto antes por las coordenadas generales de una "Antropología Filosófica", que por las coordenadas generales de una «Filosofía de la Historia». Se trataría de una "concepción antropológica de la HF».

$3 \S$. Por el contrario, según la «concepción B», la HF sería la totalización atributiva de un único género plotiniano de filosofía que se desarrolla históricamente en un curso lineal heterológico, en cuyo despliegue continuo, diversificado en fases, se concatena causalmente la serie de polémicas institucionales que une sinalógicamente entre sí a un conjunto irrepetible de instituciones filosóficas idiográficas que conviven en un mismo contexto político estatal luchando a muerte entre sí por imponer en él su definitiva victoria ideológica. «No caben dos soles brillando en el mismo cielo».

Los Estados, sobre todo aquellos cuyo movimiento histórico está determinado por una norma meta-política cuya fuerza los obliga a tener vocación universal, son "organizaciones sociales totalizadoras» que proyectan la realización de planes y programas orientados a la edificación de la conciencia

THÉMATA. Revista de Filosofía, Nº48 julio-diciembre (2013) pp.: 49-64 doi: 10.12795/themata.2013.i48.04 
individual de todos sus ciudadanos. Los sustratos idiográficos de filosofía institucional realizados históricamente en torno a la figura central de una persona, se disputan el acceso al lugar institucional del cuerpo del Estado desde el que éste pueda incorporarlas a su dispositivo ideológico meta-estabilizador de su eutaxia o buen orden político.

Esta otra «concepción B» nos presenta una HF dotada de un contenido semántico que se presta a ser envuelto antes por las coordenadas generales de una "Filosofía de la Historia" que por las coordenadas generales de una "Antropología Filosófica». Por eso dije anteriormente que mi tesis, casi con toda seguridad, agradaría más a los historiadores de profesión, tan dispuestos ellos siempre a filosofar sin saber que lo hacen, que a los propios filósofos profesionales, tan propensos actualmente a desvincular la racionalidad filosófica de cualquier forma de violencia en general y de la guerra como forma de violencia en particular.

Ahora bien, este otro contenido semántico de la HF ya no podrá ser ofrecido al público con la pretensión de reflejar verazmente con él el contenido de la verdad global que, supuestamente, habría ido desarrollado históricamente el saber filosófico desde Tales de Mileto hasta Habermas, entre otras cosas, porque la "verdad» de dicho contenido semántico, envuelto ahora por las coordenadas generales de una determinada "Filosofía de la Historia» impuesta por el sustrato filosófico que se ha alzado con la victoria ideológica, no puede ser expuesta como algo que tiene "valor cultural» en sí misma considerada, separada o desconectada de los «intereses pragmáticos» de los diferentes «grupos sociales» que están, de hecho, en tanto que «morfologías reales», luchando ideológicamente entre sí desde la plataforma institucional constituida por sus respectivos cuerpos de doctrina filosóficos.

El concepto de «lucha ideológica» lo uso aquí, como es obvio, en el sentido dialéctico de la expresión «ideología»; sentido que, como todo el mundo sabe, es el acuñado por Karl Marx. En este sentido marxista de la expresión, aunque es cierto que no toda ideología es filosófica, en cambio sí es cierto que toda filosofía, institucionalmente considerada como un cuerpo doctrinal idiográfico en estado morfológico que está implantado políticamente en el presente, es una determinada ideología enfrentada objetivamente a otras ideologías sistematizadas o no filosóficamente.

El contenido de la tesis expresada en el enunciado titular de mi comunicación, tesis que pone a «la guerra como tema trascendental de la HF», se refiere a esta "concepción "dialéctica» de la HF», y no a la "concepción A» que se le opone dioscúricamente.

Una vez advertido esto, espero que a partir de aquí ya nadie pueda ser llevado por mí a un estado de confusión que le imposibilite interpretar correctamente el sentido de la tesis. 
El sentido global de la tesis podría expresarse muy rápidamente del siguiente modo: por «razones pragmáticas» que son valiosas para el «momento existencial» de la morfología institucional de los cuerpos de doctrina filosóficos, los filósofos que cooperan en la construcción doctrinal de dichos cuerpos no pueden desentenderse de la guerra poniéndola entre paréntesis a la hora de reflexionar dialécticamente sobre la historia de su disciplina. Estas razones de orden pragmático - existencial son inseparables de los intereses ideológicos partidistas de los que los filósofos no pueden desprenderse por razones objetivas de carácter dialéctico.

Vamos a ir precisando un poco más el contenido de la tesis. En un sentido global, la precisión del contenido de la tesis que viene a continuación, tiene por objeto evitar, en este caso, que los presentes puedan deslizarse hacia una interpretación del contenido de la tesis en un sentido reduccionista. Quizás sea necesario recordar, entonces, para remarcar el camino por el que marchará la precisión que a continuación haré del contenido de la tesis, que no estoy reduciendo la Historia lisológica de la Filosofía a historia sociológica, sino que estoy envolviendo, por elevación, a la historia morfológico - institucional de la filosofía en las coordenadas generales de la Filosofía de la Historia.

Dicho esto, pasemos ya a ir precisando el significado de la tesis.

$4 \S$. En primer lugar, es preciso tener en cuenta que estoy tomando como «parámetro» de «realización institucional» de la filosofía histórica a la «realización personal», y no a la «realización impersonal» en un "gremio profesional dependiente administrativamente» del Estado. Los dos «momentos» de la sustantividad actualista de una institución filosófica idiográfica realmente existente, cuya realización institucional se produce en torno a la figura central de una persona, son los momentos que denominaré «momento semántico - subjetual» y «momento pragmático - objetual» respectivamente. Ambos momentos, disociables pero inseparables, están simultánea e inmediatamente vinculados al contenido de la "actividad proléptica» del sujeto operatorio personal que diseña originariamente la morfología institucional del cuerpo doctrinas que va a ir sistematizándose filosóficamente con el paso del tiempo. Siguiendo el orden en el que los he mencionado anteriormente, estos dos «momentos» de la realidad institucional de la "filosofía académica genitiva», pueden ser puestos en relación de correspondencia (que no identidad) con la «esencia» y la «existencia» de dicha realidad institucional respectivamente.

El «momento subjetual de valor semántico» que hago corresponder con la «esencia» o la «identidad» del cuerpo doctrinal de la institución filosófica idiográfica, es el «momento proléptico de la programación» del contenido dogmático de las diferentes "disciplinas académicas» a través de cuyo entretejimiento mutuo en symploké se irá actualizando la sustancia de dicho cuerpo doctrinal a través de los accidentes del terreno, siempre cambiantes; dicha ac-

THÉMATA. Revista de Filosofía, Nº48 julio-diciembre (2013) pp.: 49-64 doi: 10.12795/themata.2013.i48.04 
tualización se irá produciendo a medida que la sistematización doctrinal, de carácter abierto, vaya incorporando progresivamente la racionalización filosófica de los nuevos accidentes del terreno que hayan ido saliendo al paso de los movimientos prácticos del sujeto proléptico que ha diseñado originariamente la morfología del sistema. Más allá de la vida personal del demiurgo artífice de su diseño originario, el sistema filosófico podrá seguir realizando en el presente su «identidad sustancial actualista», si en dicho presente existen otros sujetos operatorios que son capaces de emularlo siguiendo sus pasos; emulación que dichos sujetos llevarán a cabo con el propósito de llevar la racionalización filosófica a lugares del territorio que están pisando y que el sujeto demiurgo del diseño originario del sistema no fue capaz de pisar en vida.

El «momento objetual de valor pragmático» que hago corresponder con la "existencia» de la morfología institucional de la filosofía histórica, es el «momento proléptico de la planificación» de las estrategias a desarrollar para conseguir las necesarias alianzas frente a terceros con otras instituciones que puedan ayudar a la institución filosófica de referencia a conseguir ocupar en el cuerpo del Estado, un «lugar» del mismo desde el que dicha institución pueda desempeñar su «papel» en relación al «conjunto del saber». Este «lugar estratégico» será el recinto institucional desde el que el sistema filosófico aplica a su cuerpo de doctrinas la fuerza de obligar de la «norma de implantación institucional» que procede originariamente del «núcleo» generador de la «esencia plotiniana» de la institución filosófica. Este núcleo generador de la esencia plotiniana de la institución filosófica es la «Academia de Platón», y la norma de implantación institucional en cuestión que procede de él, obliga a los miembros de la institución filosófica a que realicen históricamente dicha implantación institucional de un modo "político», en el sentido de que para que la institución tenga poder o fuerza para desempeñar su función educativa en el Estado, es necesario que se den alguna de estas dos cosas, a saber:

a) O bien que los que han llegado a ser filósofos por su cuenta, con independencia de la educación reglada administrada por las autoridades educativas del Estado, ocupan los cargos desde los que se ejerce el gobierno del mismo, echando de ellos a los que mantienen dichos cargos secuestrados, evitando a toda costa que el ejercicio del poder político que se realiza desde ellos pueda estar sometido a la influencia de la verdadera racionalización filosófica;

b) O bien que los que ocupan de hecho los cargos políticos desde los que se gobierna el Estado, obliguen a la fuerza a ocupar dichos cargos políticos a aquellos a los que han sometido a un proceso reglado de educación cuya finalidad última es la de formar ciudadanos que sean capaces de llegar a ser verdaderos filósofos. 
Segunda precisión: ¿qué entendemos, en este sentido, por «verdad de un sistema filosófico»? Cuando hablamos de «la verdad» de un sistema filosófico idiográfico con identidad sustancial actualista inmersa en el presente práctico, dicha verdad la ponemos en inmediata conexión con los intereses pragmáticos de la persona que usa el sistema como un mapamundi proléptico. Según esto, tanto más verdadero será un sistema filosófico, cuantos más ciudadanos del Estado conecten objetivamente sus intereses personales de carácter político con el momento pragmático - existencial de la realidad institucional del sistema filosófico. De no existir esta conexión pragmática entre el cuerpo doctrinal del sistema y el cuerpo de los ciudadanos, la verdad del sistema filosófico pierde su fundamento material, pues el contenido semántico que dicha verdad pudiera contener considerado en sí mismo, únicamente tendría valor para la minoría de individuos que co-operan intencionalmente en el sostenimiento de la sustantividad institucional actualista del sistema filosófico. Por tanto, puede decirse que tanto más verdadero será un sistema idiográfico de filosofía académica, cuanto más amplia sea su mundanización, es decir, cuanto más amplia sea su incorporación a la "maquinaria lógica» de las conciencias individuales de los ciudadanos del Estado. Un nivel de mundanización alto, significa que el cuerpo doctrinal de la institución filosófica ha conseguido ocupar, gracias a sus alianzas políticas, un lugar institucional estratégico desde el que su cuerpo de doctrinas puede ser incorporado por el Estado a su dispositivo ideológico meta-estabilizador de la conciencia moral y política de los ciudadanos.

Esta mundanización de la filosofía académica genitiva no tiene nada que ver con la desvirtuación divulgativa de su cuerpo de doctrinas, sino que está vinculada, de un modo inmediato, a la reflexión académica que se lleva cabo desde una de las disciplinas filosóficas que es parte determinante de dicho cuerpo doctrinal. Esta disciplina es, precisamente, la historia de la filosofía cuando la concebimos desde la perspectiva dialéctica de la concepción B que le he propuesto al inicio de mi exposición.

La «verdad pragmática» de un sistema de filosofía académica genitiva, sólo podrá ir «saliendo a la luz» en la medida en que el sistema filosófico de referencia sea capaz abrirse al público en general mostrándose ante la ciudadanía como un cuerpo de doctrina que, a través del «momento semántico - esencial» de su realidad institucional, entra en contacto polémico con otros cuerpos de doctrina filosóficos cuya sustantividad institucional actualista está también inmersa en el presente práctico gracias a la co-operación de algún grupo organizado de sujetos que también se esfuerzan por alcanzar algún grado de mundanización para su doctrina.

Así pues, entre las disciplinas académicas programadas por el demiurgo que diseña originariamente la morfología del cuerpo doctrinal de un determinado sistema filosófico idiográfico, tiene que haber una cuya peculiar concatenación de Ideas esté orientada a conseguir «totalizar» la cadena completa

THÉMATA. Revista de Filosofía, $\mathrm{N}^{\circ} 48$ julio-diciembre (2013) pp.: 49-64 doi: 10.12795/themata.2013.i48.04 
de sucesivas "apariciones polémicas» en público que el sistema filosófico de referencia haya tenido que ir haciendo a lo largo de su actualización en el presente frente a los otros sistemas de su misma constelación semántica. ¿Cuál es el propósito de esta totalización reflexiva a través de la que el sistema se va abriendo al público en general para ir mundanizándose? El propósito es descartar o evitar que algunos de los sistemas filosóficos con los que se polemiza, todavía activos en el entorno durante el presente práctico, acabe «sustituyendo» al sistema filosófico en el lugar estratégico en el que éste haya conseguido implantarse institucionalmente aplicando desde él a su cuerpo doctrinal la fuerza de obligar de la norma platónica de implantación institucional. Esta disciplina académica mediante la que el demiurgo de un sistema filosófico no se dispone a ir señalando nuevos accidentes del terreno, sino que se dispone a reflexionar peri-filosóficamente sobre su propia actividad proléptica, tratando de totalizar dialécticamente la identidad sustancial actualista de su propio mapa proléptico confrontándola polémicamente con la de otros mapas filosóficos también activos en el presente práctico, es, precisamente, la «historia de la filosofía", sólo que concebida no ya como un saber doxográfico exento del presente práctico, sino como un saber crítico inmerso en el presente práctico de carácter reflexivo, sistemático y esencialmente polémico, es decir, dialéctico.

En definitiva: la historia de la filosofía, según las coordenadas de la "concepción B» anteriormente expuestas, es una disciplina crítica mediante la que se puede llevar a cabo una totalización auto-referencial o reflexiva de carácter dialéctico desde la que cada sistema idiográfico de filosofía académica genitiva trata de definir su propia identidad sustancial actualista frente a la de los demás sistemas filosóficos con los que convive en el presente en constante polémica institucional.

Entendida así, en su symploké con la «Filosofía de la historia», la «historia morfológica de la filosofía institucional» tiene ya mucho que ver con la guerra.

Para empezar, podríamos comenzar diciendo que en las guerras civiles los antagonismos dialécticos entre filosofías académicas mundanizadas se simplifican y el Estado aparece fracturado en dos bandos ideológicos enfrentados a muerte. ¿Pueden desconectarse las guerras civiles de las polémicas académicas entre filosofías que se enfrentan ideológicamente entre sí con la vista puesta en el objetivo de lograr alcanzar en el porvenir el mayor nivel de mundanización posible para su doctrina? Las ideologías de los dos bandos que se enfrentan a muerte en una guerra civil ¿son «ideologías no filosóficas» o, por el contrario, son "filosofías académicas muy ideologizadas» que han conseguido alcanzar una implantación institucional lo suficientemente fuerte como para poder desarrollar históricamente líneas de mundanización de sus doctrinas que acaban siendo estructuralmente incompatibles entre sí dentro del cuerpo del Estado? 
Según la tesis que defendemos, que la filosofía es una institución cuyo despliegue histórico morfológico no puede desconectarse de la guerra, habría que concluir en muchos casos más bien lo segundo. Y entonces, tendremos que tener en cuenta, muy seriamente, por la cuenta que nos trae, que una guerra civil es siempre, a la vez, una guerra encubierta o solapada entre Estados que son solidarios con los dos bandos ideológicos que se están matando en el interior del Estado en el que la guerra civil es declarada, así como que una guerra explícitamente declarada entre Estados es siempre, a la vez, una guerra civil encubierta o solapada en el interior de cada uno de ellos.

Los filósofos no pueden desentenderse de la guerra porque su función o su papel en el Estado, está intrínsecamente vinculado a las normas pragmáticas de la educación, y la educación, como todo arte o técnica implica la violencia. Una violencia que, en el caso de la violencia educativa puede acabar desencadenando el contexto determinante para el estallido de un conflicto que, en su mayor grado de intensidad puede llegar a ser un conflicto armado.

$5 \S$. Una vez expuesto todo lo anterior voy a ir dando por concluida mi intervención formulando una serie de preguntas que espero estimulen la intervención del público asistente a este congreso.

La primera pregunta sería esta: ¿hasta qué punto podemos seguir organizando escolarmente la HF, por un lado, al modo hegeliano, como un curso lineal atributivo en el que lo concatenado causalmente en un continuo histórico son los tres periodos de la evolución inmanente del espíritu, y, por otro lado, al mismo tiempo, también al modo kantiano, poniendo entre paréntesis a la guerra, para que el continuo histórico- morfológico de la filosofía institucional, siga su curso natural impulsado por la fuerza de un Dios trascendente cuya voluntad desea la paz perpetua como destino final para la Humanidad?

Podríamos formular la anterior pregunta de este otro modo: ¿No es cierto que la institución escolar que administra el conocimiento reglado de la Historia de la Filosofía, la facultad de filosofía universitaria, es una institución desde la que se nos ha impuesto democráticamente la aplastante victoria ideológica del idealismo histórico?

¿Y no es cierto también, que la voluntad trascendente de la divina providencia kantiana, es la misma voluntad general de los soberanos cuerpos electorales que ayer mismo clamaban al unísono por todo el globo terráqueo su deseo racional de una definitiva paz perpetua?

La acción escolar efectuada por la hoy ya triunfante facultad "superior" de filosofía universitaria (de la que es obediente facultad "inferior" subordinada la filosofía que enseñamos los "letrados" en el bachillerato), ha contribuido decisivamente al establecimiento de una especie de relación de identidad sintética entre la "voz de Dios" y la "voz del Pueblo", relación de identidad que constituye lo que podríamos considerar como el teorema central del fundamen-

THÉMATA. Revista de Filosofía, $\mathrm{N}^{\circ} 48$ julio-diciembre (2013) pp.: 49-64 doi: 10.12795/themata.2013.i48.04 
talismo democrático. Un fundamentalismo democrático que nos impone dogmáticamente la paz de la victoria del idealismo filosófico (dicho sea de paso: yo no creo que los modernos Estados democráticos de Derecho estén actualmente teologizándose, llevan ya desde sus orígenes incorporada a la teología en sus fundamentos).

En definitiva: ¿qué hacer ante la paz ideológica impuesta por el vencedor que ha conseguido cancelar la polémica institucional imponiéndonos como imperativo categórico político el tener que poner obligatoriamente a la guerra entre paréntesis?

$6 \S$. Ante la pregunta sobre el qué hacer, creo que cabe adoptar dos actitudes filosóficas bien distintas que paso a exponer someramente a continuación.

El primer tipo de actitud filosófica sería una "actitud acomodaticia» al saber hacer político dominante. Desde esta actitud de acomodo al status quo político actual, se pretendería hacer hincapié en la mayor importancia del «momento pragmático existencial» de la realidad institucional de la filosofía académica. Quienes optan por este tipo de actitud, quienes ante el qué hacer optan por acomodarse en el status quo del poder político vigente, que es el poder partitocrático de los Estados Social-democráticos de Derecho, lo que se proponen es lograr que dentro de dicho status quo político actual, la institución filosófica conserve su «lugar estratégico» en la Universidad; un lugar institucional, la Universidad, consolidado ya en dicho status quo político como un lugar superior o de segundo orden, desde el que la institución filosófica puede desempeñar un "papel determinante» en relación a la educación reglada de los ciudadanos; un «papel determinante» o de "segundo orden», que envuelve al papel inferior o subordinado que en relación a dicha educación ciudadana pueden desempeñan otras instituciones filosóficas situadas en instituciones educativas inferiores o de primer orden, como es el caso de la filosofía del bachillerato.

Ahora bien, hay que tener en cuenta que el llegar a ocupar algún día en la Universidad controlada administrativamente por el Estado de Derecho ese lugar institucional superior o de segundo orden desde el que poder desempeñar, en relación a la educación, ese papel determinante era, precisamente, aquello que Kant concibió en su presente práctico como el provenir infecto de la nueva filosofía revolucionaria que él estaba tratando de sistematizar.

Pero lo que para Kant era desde su presente el provenir infecto de la filosofía, es hoy para nosotros, nuestro actual presente filosófico; un presente centrado en torno a la figura institucional de Kant. Las sucesivas oleadas de filósofos de algún modo kantianos, llegan hasta nosotros inundándolo prácticamente todo.

Así pues, desde esta actitud de acomodo que asimila con estoica paciencia la victoria del idealismo como si fuera nuestro natural destino filosófico, se tratará de asumir la victoria kantiana como un canon de implantación 
institucional para la filosofía académica. La victoria kantiana sería asumida como aquello que la Naturaleza (la Providencia o el Destino) ha dispuesto para el porvenir ya realizado de la filosofía académica. Tal es así, que desde un materialismo filosófico de base estoica con vocación universitaria, bien podría asumirse tranquilamente esta paz kantiana asimilando como propio el lema de Séneca que ya Kant hiciera suyo en la Paz Perpetua para ofrecer desde él una justificación global de su peculiar teodicea histórica: fata volentem ducunt, nolentem trahunt: el destino guía a quien obedece, arrastra por la fuerza al que se resiste.

En definitiva: lo que en el presente de Kant era para éste una facultad inferior, se habría elevado hoy, en nuestro presente, y cumpliendo el pronóstico de Kant, hasta la condición institucional de una facultad superior. Este cambio de situación institucional implica, a su vez, como es lógico, un cambio en la estructura interna de la facultad universitaria de filosofía. Este cambio lo ha detectado muy bien el catedrático de historia de la filosofía antigua de la Universidad de Murcia, Patricio Peñalver, en un magnífico artículo titulado Upsalón publicado en el número 108 de la revista Catoblepas. El cambio en cuestión consiste, según el profesor Patricio Peñalver, en que en las actuales facultades superiores de filosofía universitaria, la metafísica de las costumbres o filosofía práctica, se ha elevado hasta alcanzar implícitamente el rango de filosofía primera.

En este sentido, creo que podría afirmarse que el llamado síndrome del pacifismo fundamentalista que, según Gustavo Bueno, afecta a esa inmensa mayoría de gente que englobamos bajo el rótulo de "pueblo ilustrado y soberano", tendría su origen etiológico en la educación ética, moral y política que los futuros profesores de filosofía en la enseñanza media adquieren de la mano de los profesores universitarios que dentro de las actuales facultades de filosofía constituyen esa comunidad específica a la que ellos mismos suelen autodenominar como "comunidad ética».

Según esto, el precio a pagar por disfrutar de este acomodo en el status quo político actual, tratando de conservar dentro de él para la filosofía el papel determinante que pronosticó Kant para ella en tanto que facultad superior de filosofía académica universitaria, es el precio de la obediencia a los dictados de la legislación mundana que promulga las leyes que determinan que ha de considerarse hoy en día racional en materias relacionadas con cuestiones filosóficas. A esta legislación mundana habría que considerarla, desde esta actitud acomodaticia conservadora del papel determinante de la filosofía universitaria, como un canon de verdad: Vox Populi, Vox Dei. Los partidos políticos son los que realmente educan al pueblo, y para hacerlo cuentan, no ya con el respaldo de su autoridad absoluta, sino con el respaldo de la autoridad académica de los profesores universitarios especialistas en ética que les ofrecen su apoyo y asesoramiento. En este contexto, el papel institucional de un profesor de fi- 
losofía en la enseñanza media, se reduce al papel de un letrado que ejecuta en el aula las órdenes procedentes de sus superiores, los profesores universitarios con los que ha aprendido filosofía en la facultad.

En definitiva: si optamos por asumir esta actitud acomodaticia, conservadora del lugar de orden superior que ha alcanzado la filosofía académica universitaria sin necesidad de tener que cumplir para ello con lo exigido por la norma platónica de implantación institucional, sino más bien todo lo contrario, rechazando explícitamente el cumplimiento de dicha norma, porque pretendemos que la filosofía siga desempeñando en relación a la educación reglada un papel determinante, entonces tendremos que asumir que forma parte del destino natural de la filosofía el haberse liberado totalmente de manera definitiva de la servidumbre a la que la sometía la teología dogmática para someterse a continuación los dictados de la ideología democrática desde la que se ofrece una justificación del actual status quo político partitocrático. De sierva de la teología la filosofía habría pasado a ser sierva de la democracia. La actitud acomodaticia de la que hablamos nos invita a asumir con placidez esta otra servidumbre.

La segunda actitud filosófica, opuesta a esta primera, sería una actitud destructiva del saber hacer político a partir del que se construye y fortifica el actual status quo político. Como dice Gustavo Bueno en «El papel de la filosofía en el conjunto del saber», "la actitud filosófica es una suerte de experimento recurrente por virtud del cual tratamos de comprobar hasta qué punto es posible la revolución (...) la resignación al fatal entramado de las cosas constituye, tanto un reconocimiento de la propia incapacidad de sustitución, como una abolición de la conciencia filosófica. El escepticismo filosófico tomaría ahora la forma no ya de un escepticismo del saber, sino de un escepticismo del hacer, de un fatalismo".

Resignarse al fatal entramado de las cosas vendría a ser lo mismo que integrarse en una de las oleadas de filósofos que llegan hasta nuestro presente impulsadas por la fuerza del destino que Kant pronosticó para la filosofía académica en las sociedades democráticas: fata volentem ducunt, nolentem trahunt. Hoy, en nuestro presente, un presente en el que cristalizan ya las consecuencias desastrosas de la caída del Imperio Soviético, comienza a verse con cierta claridad que Kant quiso cortar la línea sucesoria para que ya nadie pudiera sustituirlo en su reinado. La figura de Kant se ve con claridad brillando en nuestro cielo como un astro de primera magnitud. Ya no está eclipsada por otras figuras posteriores como puedan serlo Hegel o Marx. La polémica ha sido cancelada.

Ahora bien, es necesario restablecer la línea sucesoria para poder garantizar la recurrencia histórica del experimento filosófico. Y eso pasa hoy por mantener una actitud filosófica destructiva afín al gusto por los cambios re- 
volucionarios que alteran sustancialmente el orden político vigente en cada momento.

Desde esta otra actitud destructiva, a la hora de abordar la cuestión del porvenir de la filosofía, se tendería a dar mayor importancia al momento semántico - esencial de la realidad institucional de la filosofía. Lo importante es que el lugar de la institución filosófica sea el punto desde el que un determinado cuerpo doctrinal pueda aplicar la fuerza de obligar de la norma política de implantación institucional en un sentido vectorial platónico opuesto frontalmente al sentido vectorial impuesto a la fuerza de esta norma por la rectificación kantiana de la misma.

Nada podemos precisar aquí acerca de la estructura precisa de este cuerpo doctrinal, pero sí es necesario comprometernos con la precisa determinación de su origen. Así, en virtud de este compromiso, diremos que, sea cual sea la singular estructura esencial del cuerpo doctrinal de la «filosofía del porvenir», dicha estructura no podrá alcanzar nunca un punto de su proceso de desarrollo doctrinal en el que pueda considerarse separada de su origen; es decir: sea cual sea su contenido estructural, éste no podrá cortar nunca los nexos de relación de identidad filogenética que mantiene con el cuerpo de doctrinas diseñado por Karl Marx en el papel de demiurgo trascendental que atraviesa sucesivas oleadas de filósofos sometidos al influjo de sus doctrinas.

Desde esta otra actitud destructiva inseparable del marxismo, el porvenir de la filosofía no se entiende ya como un porvenir perfecto, ya realizado, sino que se entiende como un provenir infecto, que está por realizar y que, desde la perspectiva semántico - esencial, estaría conectado, de un modo u otro, al contenido doctrinal del materialismo filosófico de Marx.

Los resultados semánticos obtenidos de la inversión del orden sintáctico en el que Marx expone literalmente o literariamente sus doctrinas en sus libros, podrán ir acumulándose a lo largo de sucesivas oleadas generacionales, en la construcción de un edificio doctrinal en cuya estructura las tesis de Marx seguirían estando presentes, solo que vueltas del revés. Ahora bien, esta vuelta del revés de Marx no sería otra cosa distinta de una permanente revolución conservadora del propio materialismo filosófico marxista en el sentido genuino de la expresión; una revolución teórica cuyo propósito sería actualizar el marxismo, ponerlo siempre al día para que sea cada vez un cuerpo doctrinal más sano y vigoroso. Se trataría pues, de no aceptar que el marxismo esté en crisis porque no es ninguna enfermedad que corrompe la vigorosidad del capitalismo en el que el idealismo se alza victorioso; aceptar esto sería tanto como conceder demasiado al adversario. No es el cuerpo doctrinal materialista que tiene su origen en el marxismo el que está corrompido, descompuesto, en crisis. Como reconoce el profesor Patricio Peñalver en el artículo anteriormente citado, lo que está en crisis es, precisamente, el cuerpo doctrinal filosófico que se ofrece hoy día desde las facultades de filosofía universitaria.

THÉMATA. Revista de Filosofía, Nº48 julio-diciembre (2013) pp.: 49-64 doi: 10.12795/themata.2013.i48.04 
Afirmar que sin ocupar un lugar en la Universidad la filosofía académica de tradición platónica pierde toda posibilidad de seguir existiendo, me parece afirmar demasiado. Es suficiente con afirmar que, de perder dicho lugar privilegiado, lo que la filosofía académica pierde son probabilidades de seguir existiendo. Así, aunque la probabilidad de seguir existiendo en la Universidad sea cada vez menor a medida que avanza el progresivo estado de corrupción conservativa de la filosofía universitaria, en cambio, la posibilidad de seguir existiendo fuera de la Universidad se mantendría intacta. Negar esta posibilidad sería tanto como negarle el porvenir a la filosofía académica en el sentido platónico de la expresión.

Así que, desde una actitud destructiva, solidaria con el espíritu revolucionario de la filosofía marxista, afirmamos que en el porvenir de las sociedades democráticas de mercado pletórico capitalista, la filosofía académica de tradición platónica seguirá existiendo porque su existencia es posible. Ahora bien, su lugar institucional ya no será un «lugar unívoco» de «orden superior» desde el que pueda desempeñar un papel determinante en relación a la educación reglada y controlada administrativamente desde las instituciones educativas de las que es titular el Estado Social-democrático de Derecho, sino que su «lugar estratégico» tendrá que ser un «lugar multívoco»; en estas sociedades, la filosofía académica podrá seguir existiendo, pero ocupando múltiples lugares integrados todos ellos en un mismo orden de importancia institucional, entre ellos la propia Universidad, pues aunque su existencia en la Universidad sea cada vez menos probable, la corrupción de la filosofía universitaria no puede llegar hasta un punto tal en el que queda aniquilada completamente su posibilidad de existir en este recinto aunque sea de forma aislada y gracias a honrosísimas excepciones. Por razones de orden pragmático - existencial, no es prudente defender que la filosofía deje de ser una especialidad universitaria. La Universidad puede ser un lugar más entre otros de un mismo orden de importancia institucional desde el que la "filosofía del porvenir» pueda desempeñar su papel educador demoledor o destructivo del saber hacer político actual. La cuestión es que, para ello, tiene que contravenir los ambiciosos deseos del maestro Kant, volviendo a su modesta condición institucional de facultad inferior cuya absoluta libertad ha de resultar ser siempre molesta para los intereses de los poderosos.

Pero la educación en relación a la cual la filosofía académica desempeñará en el porvenir su destructivo papel desde su localización es estos múltiples lugares integrantes o de primer orden, será una "educación difusa" antes que reglada; una educación que se desarrollará espontáneamente por aquí y por allá, sin ningún tipo de control administrativo por parte de las instituciones educativas dependientes del Estado Social - democrático de Derecho.

Desde esta actitud destructora abierta al porvenir infecto de la filosofía académica, proponemos rescatar los componentes semánticos de la guerra 
para volverlos a integrar en una Idea filosófica desde la que nos sea posible enfrentarnos dialécticamente con el kantiano y pre-marxista pacifismo fundamentalista, interpretado aquí como un síndrome o conjunto de síntomas que ponen de manifiesto una enfermedad ideológica de las sociedades de nuestro tiempo diagnosticada por Gustavo Bueno con el nombre de fundamentalismo democrático. Es el síndrome del pacifismo fundamentalista el que mantiene recluido el contenido semántico de la guerra bajo el dominio institucional de las ciencias naturales que estudian los fundamentos biológicos de las conductas humanas. Hay que rescatar ese contenido semántico de la guerra para devolverlo organizado en forma de Idea filosófica al seno de las coordenadas generales de una Antropología Filosófica que esté integrada, junto a las de una Filosofía de la Historia, en el dintorno de un cuerpo doctrinal materialista de estirpe irrenunciablemente marxista.

Como se ha dicho aquí en este congreso, los filósofos no pueden mirar para otro lado cuando salta a la vista el dolor antropológico que está produciendo aquí, en nuestras ciudades, la violencia económica capitalista. Una violencia económica moderna que, por cierto, según Kant, dicho sea de paso, debía ir sustituyendo progresivamente a la guerra a medida que fuera realizándose asintóticamente en el mundo entero, el proyecto político ilustrado de la paz perpetua.

\section{Bibliografía:}

-Bueno, Gustavo:

El papel de la filosofía en el conjunto del saber, ed. Ciencia Nueva, 1970. ¿Qué es la filosofía?, ed. Pentalfa, 1995.

-Kant, Inmanuel:

Hacia la paz perpetua, ed. Biblioteca Nueva, 1999.

De la relación entre teoría y práctica en el Derecho Político, en Teoría y práctica, ed. Tecnos, 2006.

El conflicto de las facultades, ed. Alianza, 2003.

-Marx, Karl:

Grundrisse, Tomos I y II, ed. Comunicación.

El Capital, Tomos I,II y III, ed. Fondo de Cultura Económica, 1992.

Crítica a la Filosofía del Estado de Hegel, ed. Grijalbo, 1978.

Crítica del Programa de Gotha, ed. Ricardo Aguilera, 1971. 